\title{
ABSTRACTS
}

\section{RESEARCHES ON ISOLATED VILLAGE SCHOOL-CHILDREN}

\author{
Institute of Educational Psychology, Tohoku University \\ [I] THE RESULT OF “NEED TEST" ON ISOLATED \\ VILLAGE SCHOOL-CHILDREN
}

By Tsukata, Takeshi and Kubota, Masand

We studied the psychological life space of the children in isolated villages in the light of a "Need Test", a questionnaire by pencil and paper method.

The questions were directed to (1) what would you like to have, (2) what would you like to do, and (3) what would you like to be, if whatever you wish were possible to be satisfied.

Investigations were held in four remote parts of Tohoku district. The subjects, 777 pupils in total, consisted of 4 th year and 6 th year pupils of primary schools, and 2nd year pupils of junior high schools. 23.7 town pupils were examined in the same way for the purpose of comparison.

The result shows that the variability of village children's responses tends to be restricted to matters familiar to them, despite the limitless possibility offered to their answering. For example, in the responses to the first question, we find many trivial articles, such as a "pencil", " notebook", " rubber eraser", which they do not miss at home or at school; and to the second question, many domestic tasks which they are actually doing as daily routine. Such tendency was more eminent in the 4th year children than in the children in upper grades, and more persistent in girls than in boys.

We interpret the result as showing that the life space of isolated village children is lowly differentiated; and their mental development is conditioned to delay.

\section{[II] INTELLECTUAL DEVELOPMENT OF CHILDREN AND PRE-ADOLESCENTS IN ISOLATED VILLAGES}

\section{By Nakajima, Tsutomu}

It has been reported by forgoing investigators that level of intelligence is generally lower than in rural school chidren.

Our problem. was to ascertain the level of 